\title{
Influencing Factor Analysis and Demand Forecasting of Intercity Online Car-Hailing Travel
}

\author{
Jincheng Wang ${ }^{1}$, Qunqi Wu ${ }^{1} \oplus$, Feng Mao ${ }^{2}$, Yilong Ren ${ }^{3, *}$, Zilin Chen $^{3}$ and Yaqun Gao ${ }^{4}$ \\ 1 School of Economics and Management, Chang'an University, Xi'an City 710064, China; \\ wangiincheng@chd.edu.cn (J.W.); wqq@chd.edu.cn (Q.W.) \\ 2 Tsinghua Shenzhen International Graduate School, Tsinghua University, Shenzhen 518055, China; \\ mf19@mails.tsinghua.edu.cn \\ 3 School of Transportation Science and Engineering, Beihang University, Beijing 100191, China; \\ chenzilin07@buaa.edu.cn \\ 4 School of Economics and Management, Tianjin Vocational Institute, Tianjin 300410, China; \\ gaoyaqun@th.tjtc.edu.cn \\ * Correspondence: yilongren@buaa.edu.cn
}

Citation: Wang, J.; Wu, Q.; Mao, F.; Ren, Y.; Chen, Z.; Gao, Y. Influencing Factor Analysis and Demand Forecasting of Intercity Online Car-Hailing Travel. Sustainability 2021, 13, 7419. https://doi.org/ $10.3390 /$ su13137419

Academic Editors: Wann-Ming Wey and Marco Manzone

Received: 21 May 2021

Accepted: 25 June 2021

Published: 2 July 2021

Publisher's Note: MDPI stays neutra with regard to jurisdictional claims in published maps and institutional affiliations.

Copyright: (c) 2021 by the authors. Licensee MDPI, Basel, Switzerland. This article is an open access article distributed under the terms and conditions of the Creative Commons Attribution (CC BY) license (https:// creativecommons.org/licenses/by/ $4.0 /)$.

\begin{abstract}
Online car-hailing travel has become an important part of the urban transportation system and is gradually changing the mode of intercity travel. Analyzing and understanding the influencing factors of intercity online car-hailing travel hold great significance for planning and designing intercity transportation and transfer systems. However, few studies have analyzed the influencing factors of intercity car-hailing travel or forecast travel demand. This paper takes trips between Yinchuan and Shizuishan, China, as the research case and analyzes the influence of time, space, passengers, and the environment on intercity online car-hailing travel. The relationship between the urban built environment and intercity online car-hailing travel demand is also investigated through a geographically weighted regression (GWR) model. We find that the peak hours for intercity car-hailing trips are between 9:00 and 10:00 and between 16:00 and 18:00, which are significantly different from those for intracity trips. Weather conditions strongly affect the mobility of intercity trips. The urban built environment also has a significant impact on intercity car-hailing ridership, and residential districts and transportation facilities are the factors with the greatest influence on intercity online car-hailing travel. These results can provide practical help to city managers improve the management of intercity traffic and develop better transportation policies.
\end{abstract}

Keywords: intercity car-hailing travel; influencing factor analysis; geographical weighted regression; urban built environment

\section{Introduction}

Due to its convenient online booking services and door-to-door pickup and drop-off services, the emerging travel mode of online car-hailing has become an important choice for people to travel in the city. China's Ministry of Transportation reported that China's online taxi regulatory information interaction platform received a total of 660 million orders in November 2020, and most of these car-hailing orders involved intracity travel.

In recent years, China has elevated its urban agglomeration development strategy to a new level. The Yangtze River Delta, the Pearl River Delta, and the Beijing-TianjinHebei urban agglomeration have become the engine of China's rapid economic growth. With improvements in road networks and enhanced transportation convenience, intercity travel behaviors such as commuting to workplaces across cities and going to and from international airports have become increasingly common. In turn, this trend has stimulated growth in intercity car-hailing demand. Thus, research on intercity car-hailing travel holds great significance.

However, few studies have investigated intercity car-hailing travel. Most likely, the reason is the limited availability of intercity travel data. Similar to intracity travel analysis, 
it is critical to analyze the factors that influence online car-hailing trips and to study the relationship between the urban built environment and intercity car-hailing travel. The analysis in this paper can provide practical help to improve intercity traffic management and to develop better transportation policies.

Decades' worth of extensive studies have investigated the factors affecting traveling behavior. Questionnaire investigations were employed by early researchers. Cervero et al [1] analyzed three factors of the impact of the built environment on traveling behavior: density, diversity, and design. Later, in 2001, four additional factors were added by Ewing et al. [2]: destination accessibility, the distance to transit, demand management, and demographics. Questionnaire investigations were soon replaced by information technology, which has better efficiency and accuracy. Schaller et al. [3] developed multiple regression models to meet taxi requirements using Global Positioning System (GPS) data. Subsequently, Pan et al. [4] Tang et al. [5], Yao et al. [6], Liu et al. [7], and Yang et al. [8] conducted research based on GPS data, aiming to analyze the spatial and temporal factors of taxi cabs. In addition, numerous studies [9-11] have investigated the impact of primary land use factors on online car-hailing ridership with Didi or Uber. In this article, we utilized online car-hailing GPS data to mine intercity ridership.

Recently, scholars have conducted many studies on the factors that influence urban traffic trips based on online car-hailing GPS data. Cerveroet et al. [1] found that vehicle miles traveled (VMT) is the most relevant factor to destination accessibility. Wang et al. [12] concluded that bus trips are most affected by the distance to transit and the street network design. Li et al. [13] found that entertainment districts and residential districts are the factors with the greatest influence on night-time online car-hailing travel, and the land use mix was also found to have a positive effect. However, all the studies above mainly focus on different areas within a city, and very few studies have analyzed the influencing factors of intercity car-hailing travel. By analyzing intercity travel data, we found that the peak hours for intercity car-hailing trips are between 9:00 and 10:00 between and 16:00 and 18:00, which are significantly different from those for intracity trips. Moreover, intercity online taxi trips are largely influenced by weather, which is very different from the characteristics of intracity trips.

To better understand the influencing factors of intercity online car-hailing travel, it is essential to determine whether the factors that influence intracity travel are still applicable to intercity travel, as well as the important factors that influence intercity online car-hailing travel. Based on intercity car-hailing data, we classified influencing factors into four types, i.e., spatial factors, temporal factors, passenger-related factors, and weather factors, and we analyzed the importance of these factors for intercity car-hailing travel.

On the other hand, some early studies have shown that the urban built environment plays an important role in urban travel $[2,14,15]$, together with population density and land use [16,17]. Pan et al. [4] studied the influences of 8 types of land use patterns: train/coach stations, hospitals, commercial districts, office buildings, campuses, scenic spots, entertainment districts, and residential districts. Among them, the number of residential districts was nearly five times that of other categories. Sun et al. [9], Li et al. [14], and Zhang et al. [10] investigated ten types of urban built environments but did not describe the classification standard of destinations. To the best of our knowledge, most studies have not provided clear explanations of the classification of the urban built environment.

To address the issue above, we performed a comprehensive review of papers and classified urban built environments. A recent study [18] pointed out that researchers have replaced land use factors with points of interest (POIs). Inspired by Jiang et al. [19], we categorized POIs into 13 types based on Amap and previous papers [4-7,9,10]: catering POIs, healthcare POIs, recreational and entertainment POIs, tourist destination POIs, residential POIs, accommodation POIs, finance and insurance POIs, cooperative and business POIs, government POIs, educational and cultural POIs, and transportation POIs.

Some researchers have also used regression models to explore the influence of the built environment on ridership, such as ordinary least squares (OLS) $[8,20,21]$ models and two- 
stage least squares (2SLS) regression [3]. Traditional methods of passenger travel demand analysis mainly include global regression methods [22,23], which assume that all variables are stationary and independent across the study area and ignore spatial heterogeneity. Geographically weighted regression (GWR) models overcome this shortcoming by allowing independent variables to alter spatially. A GWR model effectively reveals the spatial variation in the influence coefficient across a study area [4,5], and GWR models have been widely used for transportation planning $[6,7,24,25]$. Therefore, in this paper, we choose a GWR model to analyze the relationship between the urban built environment and intercity online car-hailing travel and to explore how the built environment influences intercity online car-hailing travel.

To conclude, we focus on analyzing the factors that influence online car-hailing trips and studying the relationship between the urban built environment and intercity carhailing travel based on intercity car-hailing data. First, we investigate whether the factors that influence intracity travel are still applicable to intercity travel, as well as the important factors that influence intercity online car-hailing travel. Second, we classify the urban built environment based on Amap and previous papers. Third, we adopt a GWR model to analyze the relationship between the urban built environment and intercity online car-hailing travel and predict intercity travel demand. The purpose of this paper is to fully study the characteristics of intercity car-hailing travel, and to make a more accurate prediction of intercity travel demand. We hope that the analysis of influencing factors of intercity travel and the prediction of travel demand in this article can help city managers better plan for intercity transportation facilities and improve travel policies. At the same time, our research can also help online car-hailing companies more accurately deploy vehicles for intercity travel in time and space, so as to make full use of public resources.

The rest of this paper is organized as follows. Section 2 describes the study data, and Section 3 provides a detailed analysis of the factors that influence intercity car-hailing travel. Section 4 uses a GWR model to forecast the demand for intercity online car-hailing travel. Section 5 summarizes the content of this research and suggests future research.

\section{Data Description}

\subsection{Study Area}

This paper studies the factors that influence intercity travel between Yinchuan and Shizuishan, which are both located in the Ningxia Autonomous Region in Northwest China. The study area is shown in Figure 1. Yinchuan (105.82-106.88 E longitude, 37.59_ $38.88 \mathrm{~N}$ latitude) is the capital of Ningxia and an important central city in Northwest China. At the end of 2019, Ningxia had a resident population of over two million people. Shizuishan (105.96-106.97 E longitude, 38.60-39.39 N latitude) is located north of Yinchuan and has a resident population of approximately 800,000. Using the case of trips between Yinchuan and Shizuishan, this study on the influencing factors of intercity online carhailing travel is important for planning and designing intercity transit systems. To explore the impact of the urban built environment on intercity car-hailing trips at a fine-grained scale, we divide the study area into 60,000 grid units, with each unit having a size of $500 \mathrm{~m} \times 660 \mathrm{~m}$. In particular, since the origins and destinations of intercity carpool trips are mainly concentrated in towns, this paper chooses the urban areas of Ningxia and Shizuishan as the study area and does not consider the rural areas between the central towns. The final study area contains 978 grid units.

\subsection{Intercity Car-Hailing Data}

The intercity car-hailing dataset contains 224,822 orders for intercity car-hailing trips between Yinchuan and Shizuishan, spanning the period from January to December 2020. The data coverage area of this paper is consistent with the study area. Each trip order record includes the pick-up and drop-off location, the number of passengers, passenger demographic information (including gender, etc.), and time information. Based on the Chinese age division standard, we divide the age of passengers into 5 age groups: chil- 
dren (0-12), youths (13-18), adults (19-35), middle-aged individuals (36-59), and elderly individuals (60 and above). The data fields and descriptions are shown in Table 1.

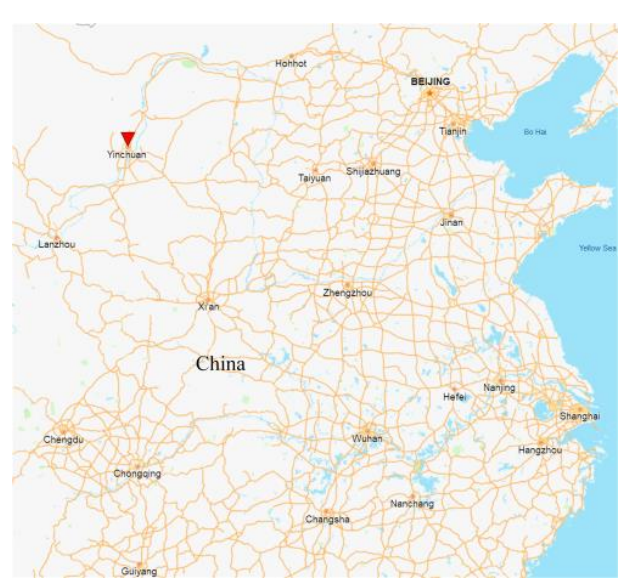

(a)

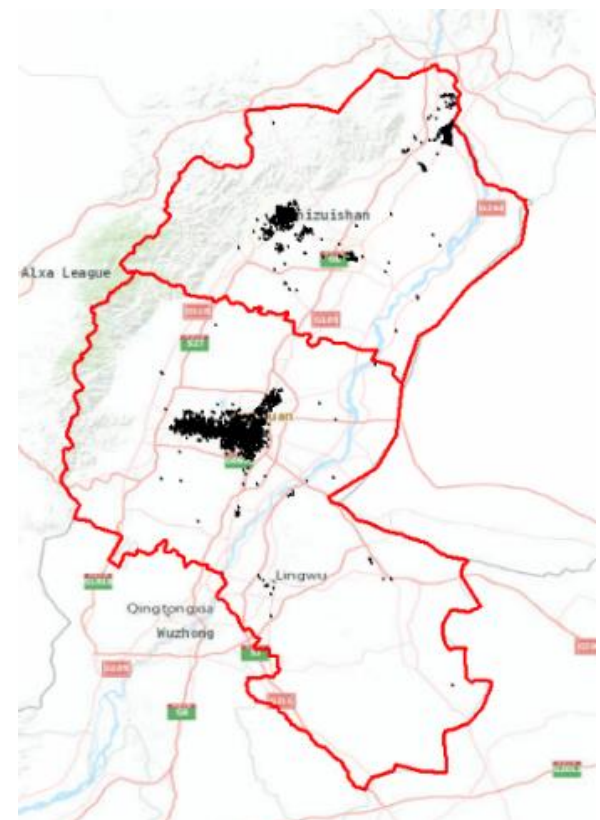

(b)

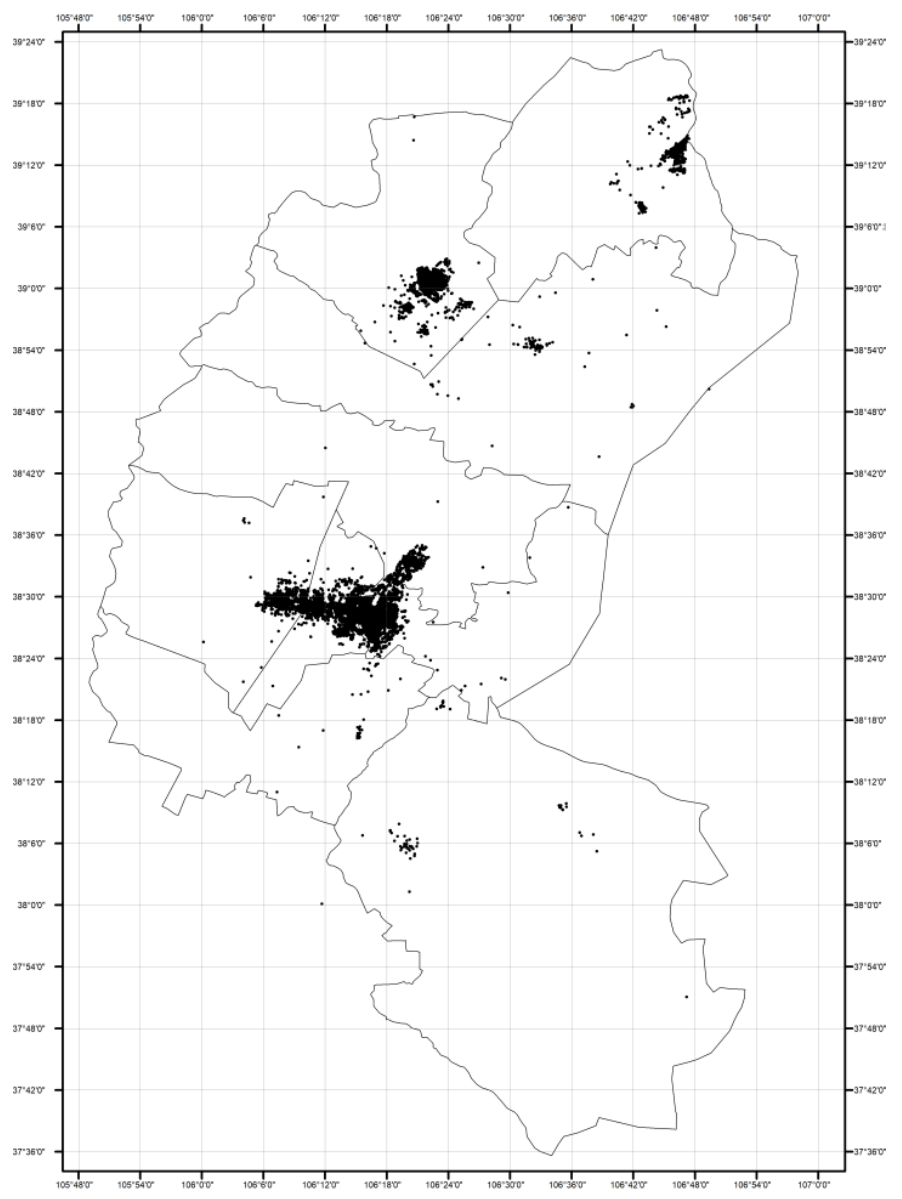

(c)

Figure 1. The study area. (a) The location of the study area in China. (b) Map of the study area. (c) Grid units of the study area. 
Table 1. Intercity car-hailing data fields and descriptions.

\begin{tabular}{cc}
\hline Fields & Description \\
\hline Order time & Passenger online order time \\
Departure time & Departure time after passenger boarding \\
Departure location & Latitude and longitude of the departure location \\
Destination & Latitude and longitude of the destination \\
Order Status & Whether the order is completed or not \\
Number of passengers & Number of passengers in the order \\
Age of passengers & Age of each passenger in the order \\
\hline
\end{tabular}

\subsection{Urban Environment Data}

POI data are obtained from Amap, which is one of the largest digital map service providers in China. In this paper, we consider 13 different types of POIs: catering POIs, healthcare POIs, recreational and entertainment POIs, tourist destination POIs, residential POIs, accommodation POIs, finance and insurance POIs, cooperative and business POIs, government POIs, educational and cultural POIs, and transportation POIs. We also consider gross domestic product (GDP) and population density.

To study the effect of weather on intercity travel, we obtain weather conditions based on the order time and location of the intercity travel data. In this paper, the weather conditions are divided into 6 categories, of which sunny, overcast, and cloudy are three independent categories. Light rain, medium rain, heavy rain, and thunderstorms are recorded as rain. Light snow, medium snow, and heavy snow are recorded as snow. Fog, hail, sand, and dust are recorded as extreme weather.

\section{Influencing Factor Analysis}

Studies have shown that urban traffic trips are heavily influenced by urban built environments. $[2,4,9,10,14,15,19]$. Based on these studies, we gathered the spatial features of car-hailing activities, i.e. the origins and destinations of passengers. Next, we classified these spatial features into 13 different Point Of Interest (POIs). Besides POI, we also explored all other possible factors that could impact car-hailing activities. Some of these factors includes time of the day, days of the week, weather, temperature, wind directions, distance traveled, number of passengers per trip and ages. Out of all possi-ble factors, our analysis shown that certain factors, such as peak hour period that affects the availability of vehicles, weather that affects passenger's mobility and willingness to travel, passenger's age which affects the locations and time of travel, affected intercity online car-hailing travel with greater significances and hence were isolated. In this sec-tion, isolated influencing factors were classified into four major categories, namely spa-tio-temporal factors, passenger-related factors, and environmental factors and presented our findings accordingly.

\subsection{Spatio-Temporal Factors}

Spatial factors and temporal factors often complement each other in explaining carhailing activities and hence will be analyzed together. Figure 2 indicates that residential districts are the most frequent taxi pick-up and drop-off hotspots, followed by transportation facilities, which include an airport and railway stations. Yinchuan Hedong International Airport is located in Yinchuan and is responsible for providing airway transportation to the residents of both Yinchuan and Shizuishan, where the latter has to make intercity trips.

Two peaks can be identified from the hourly trip distribution plotted in Figure 3a. The first peak is the morning peak period between 08:00 and 10:00. The second peak increases starting at 16:00. It reaches the highest point at 17:00 and drastically plummets thereafter. These findings highlight that most trips are made in the day, which implies that passengers tend to not travel by taxi at night. The first peak can be identified as the morning peak hour period. Based on the highest point of the second peak, the evening peak is identified as the period between 16:00 and 18:00. The two peaks exhibit a typical M-shaped pattern. 


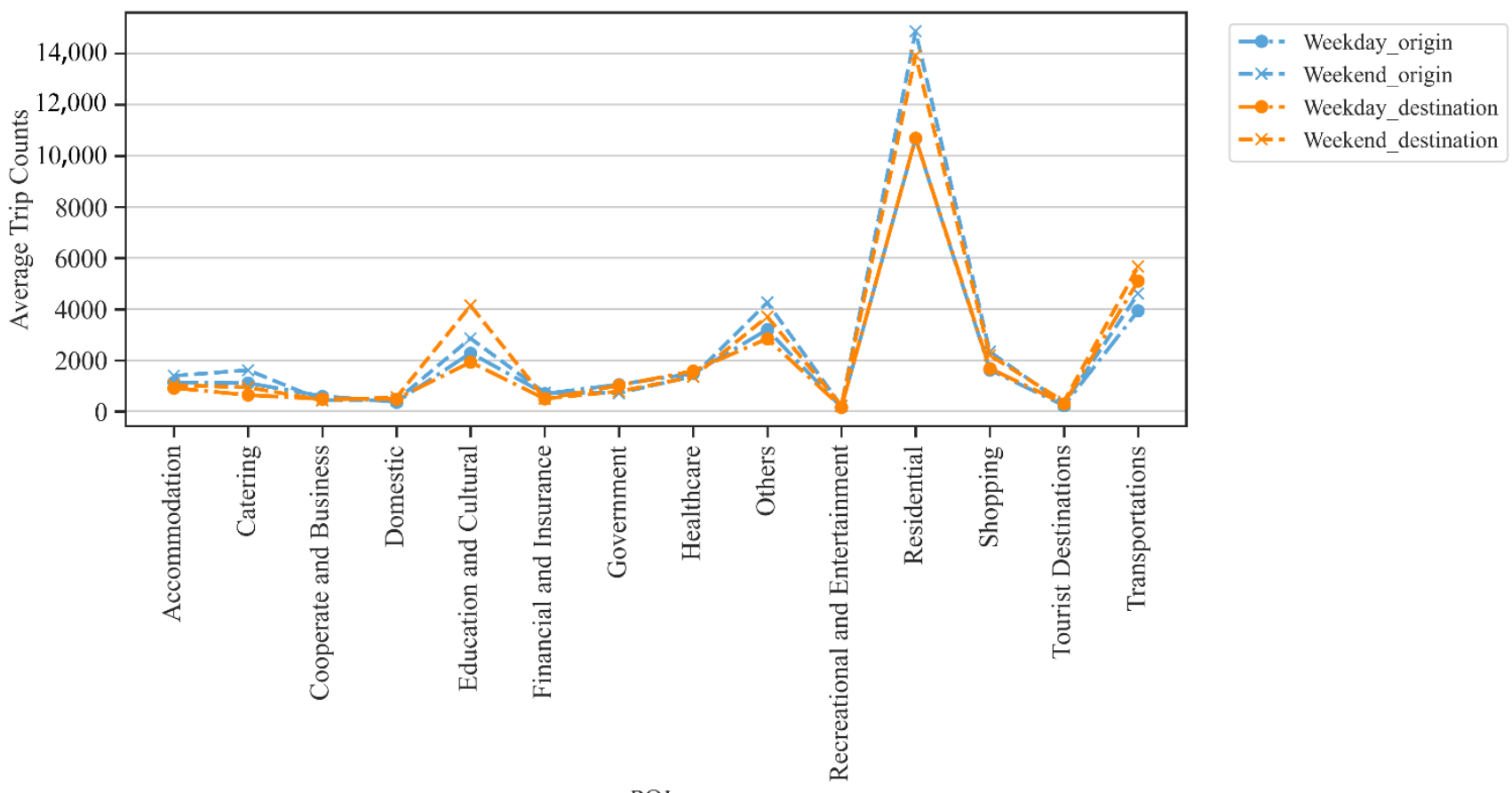

POIs

Figure 2. A comparison of trip counts between POIs on weekdays and weekends. The data are averaged based on the number of days of weekends and weekdays. Residential districts are responsible for the most trips, followed by transportation facilities and educational and cultural facilities. 14,000 12,000 10,000.

The further breakdown of the hourly trip distribution based on POIs in Figure 4 illustrates that more passengers travel to transportation facilities in the morning than in the evening. An opposite trend can be observed in residential districts, which receive more passengers in the evening. More travelers leave residential districts in the morning before 10:00 compared to the evening peak. In addition, more travelers travel to transportation facilities. It can be deduced that this might be the period when residents leave their houses and start their day. Railway and airway transportation are more frequent in the morning, which accounts for the larger number of trips departing for transportation facilities in the morning. Towards the end of the day, more residents are going home, leading to the increment in trip counts heading to residential districts at approximately 17:00. As most residents reach home, trip demand decreases and causes a sudden drop in trip counts after 18:00.

The weekly distribution plot in Figure $3 b$ demonstrates a high trip volume on Fridays, Saturdays, and Sundays. A more detailed plot based on POIs in Figure 5 further illustrates an interesting phenomenon where departures from and drop-offs at residential districts increase as the weekend approaches and drop after Mondays. A closer analysis finds a high volume of passengers arriving at residential districts on Fridays and departing from residential districts on Sundays. This finding may suggest weekend traveling habits. A higher portion of passengers visit educational and cultural facilities on Sundays. Such locations include museums and educational centers, which often have larger crowds on weekends. 


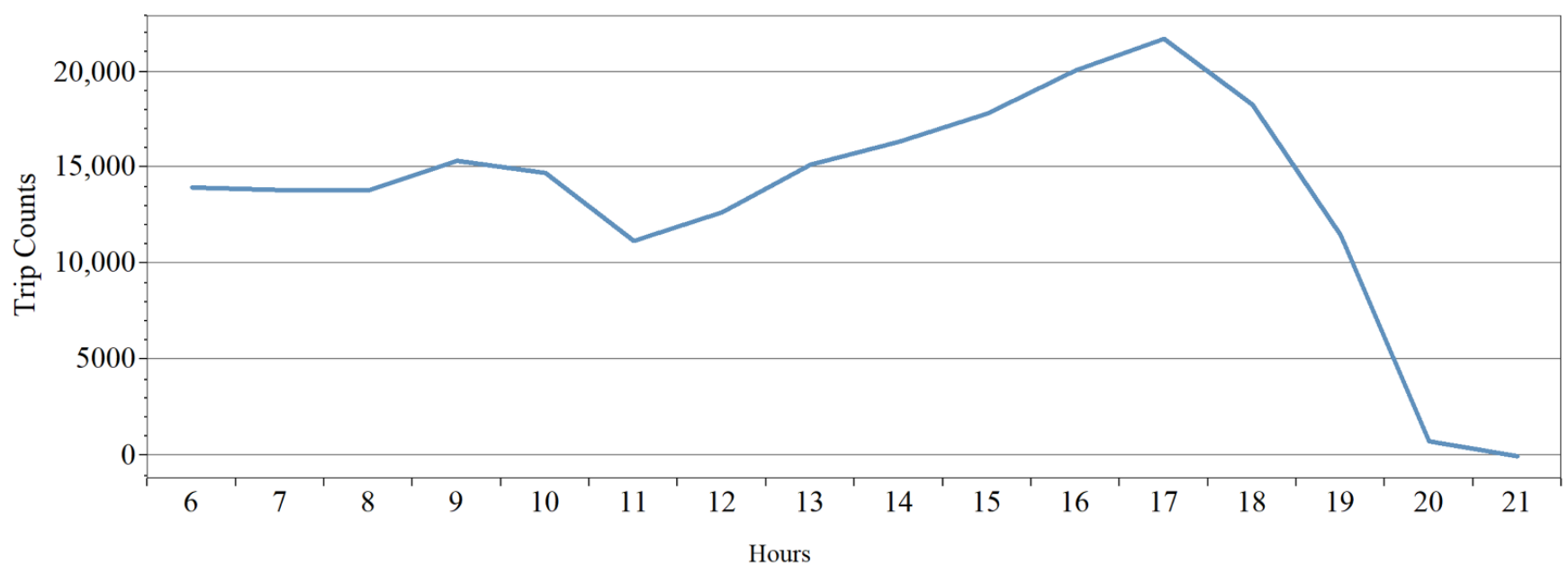

(a)

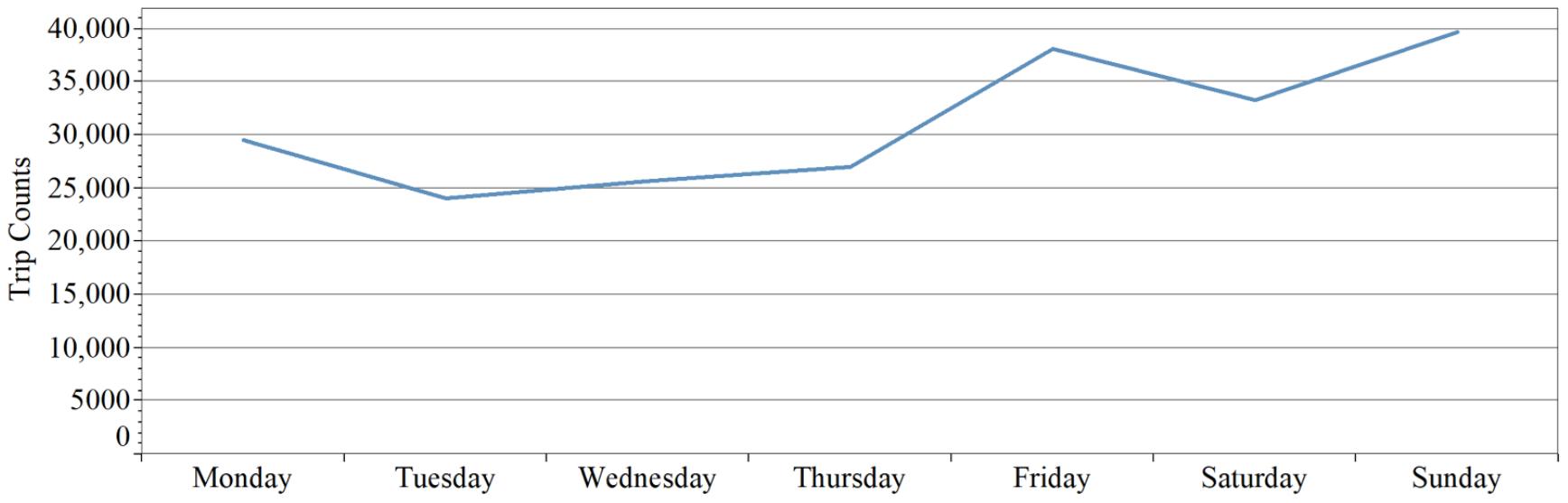

Weekdays

(b)

Figure 3. (a) A visualization of the distributions of trips over hours of the day. The first peak occurs between 8:00 and 10:00, and the second peak occurs between 16:00 and 18:00, revealing the rush hour periods of the cities. (b) A visualization of the distributions of trips over a week, revealing an increment in trip counts towards weekends.

Trips were further grouped into three periods, namely the morning peak (8:00-10:00), the evening peak (16:00-18:00), and the off-peak periods. The groups were plotted in Figure 6 with data averaged based on the number of hours included in the period. The grouping reveals a significant difference in trip counts between the three periods, where most people commute during the evening peak, regardless of whether the day is a weekday or a weekend day. This finding suggests that there is higher taxi demand during evening peak hours. 


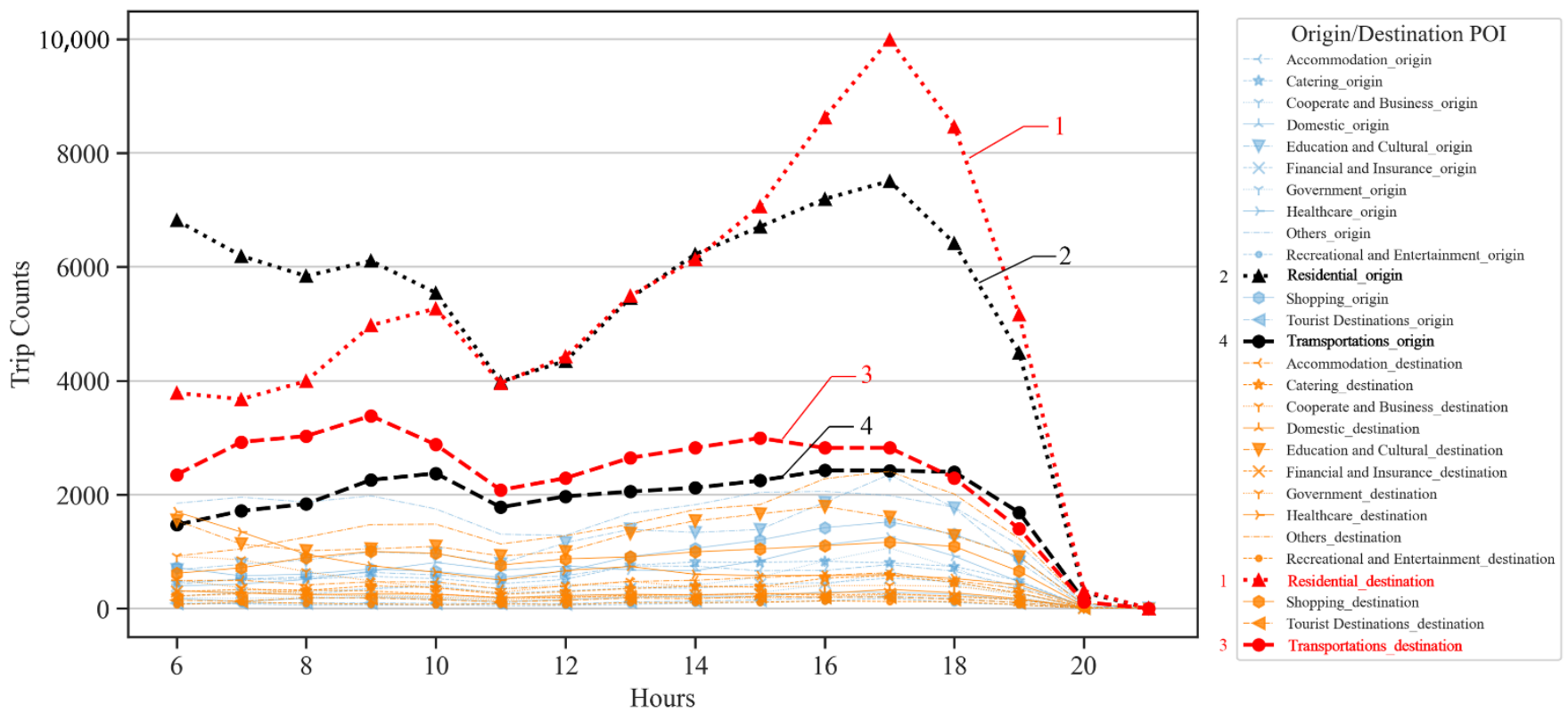

Figure 4. Distribution of POIs over different hours of the day. Residential districts dominate the trip counts for both destinations and origins.
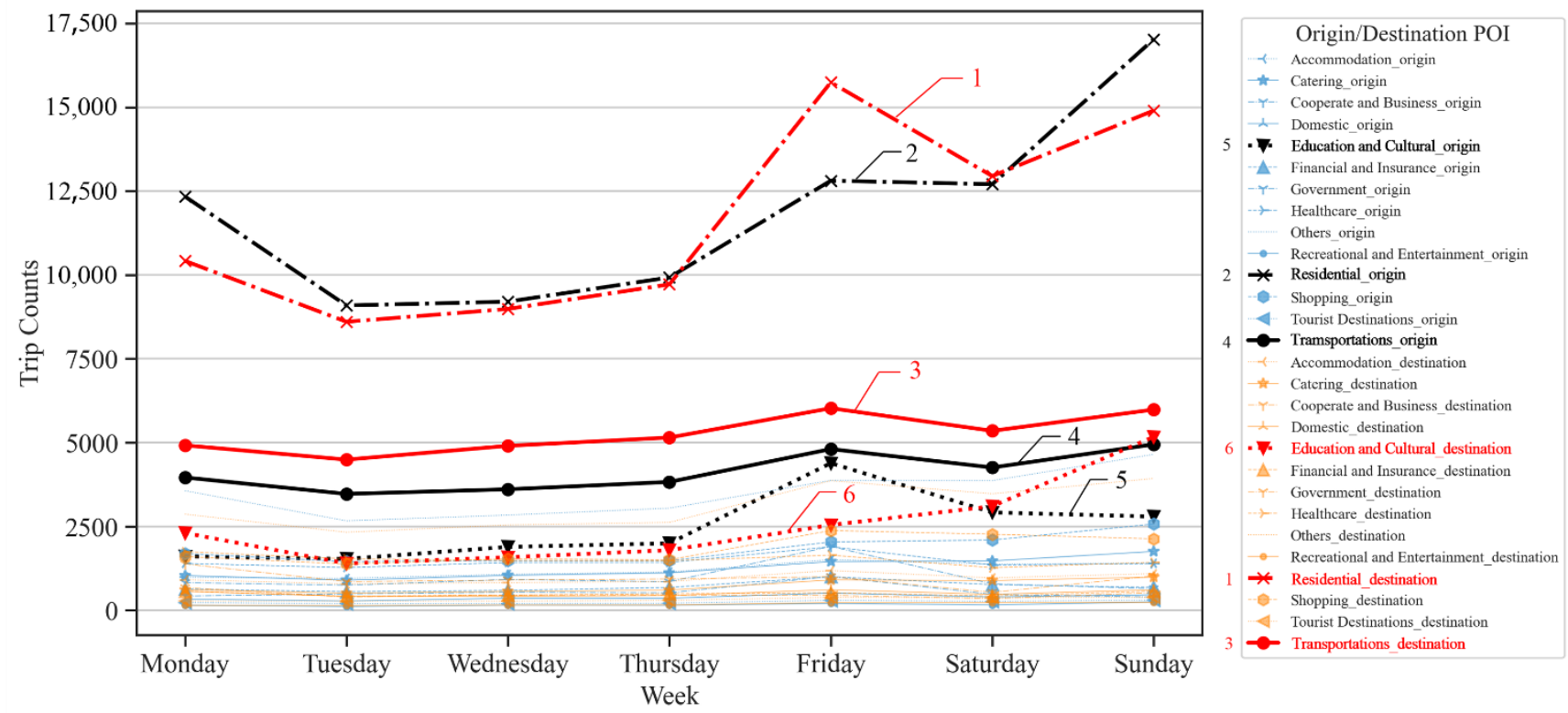

Figure 5. A visualization of the distributions of trips over the days of the week. There is an increment in trips related to residential districts as the weekend approaches. 


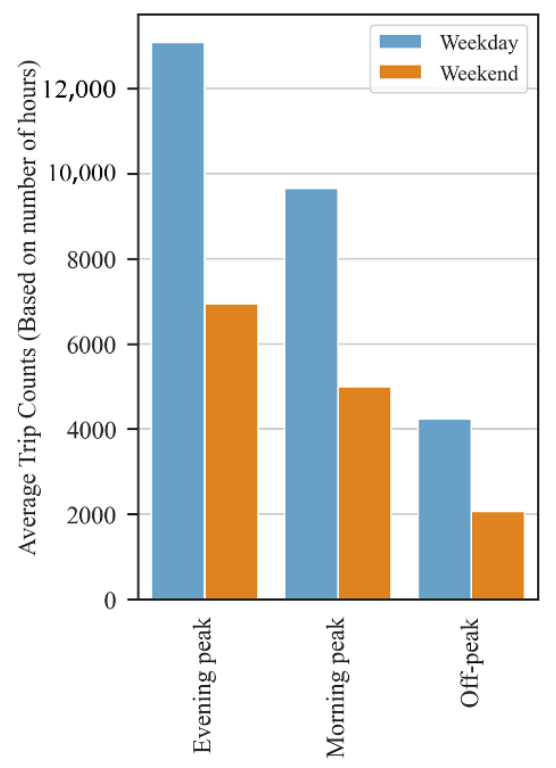

Figure 6. A plot demonstrating the trip counts of three periods. The evening peak is the period in which most trips occur, regardless of whether the day is a weekday or a weekend day.

\subsection{Passenger-Related Factors}

Passenger-related factors refer to characteristics of passengers, such as age, number of passengers per trip, that affect car-hailing activities. For instance, a passenger's age may affect the location and time of travel. Passengers are divided into different age groups, namely children, youths, adults, middle-aged individuals, and elderly individuals. Figure 7 illustrates the different POI preferences of each age group. In general, single-passenger trips are the most common for every age group. There is a higher tendency for elderly individuals and children to travel with others. The percentage is two times higher than that of other age groups. This finding may be attributed to the fact that people belonging to these two age groups require more people to accompany them. Additionally, booking is usually performed with mobile phones, which may present some challenges for these groups. Based on Figure 8, compared to other age groups, youths and children travel more often on weekends. which may be due to schooling activities on weekdays. This observation is supported by Figure 9, which reveals that a higher percentage of youths make trips related to educational and cultural facilities.

Lapsed time, which is time differences between the order time and the departure time, demonstrated passenger's tendency to make bookings prior to departure. For trip times that are less than an hour, passengers usually make same-day bookings. Within the same day, $37 \%$ of trips $(79,771)$ were booked less than an hour before departure. Passengers usually make impromptu trips and tend to plan their trips when the trip time is longer than an hour. 


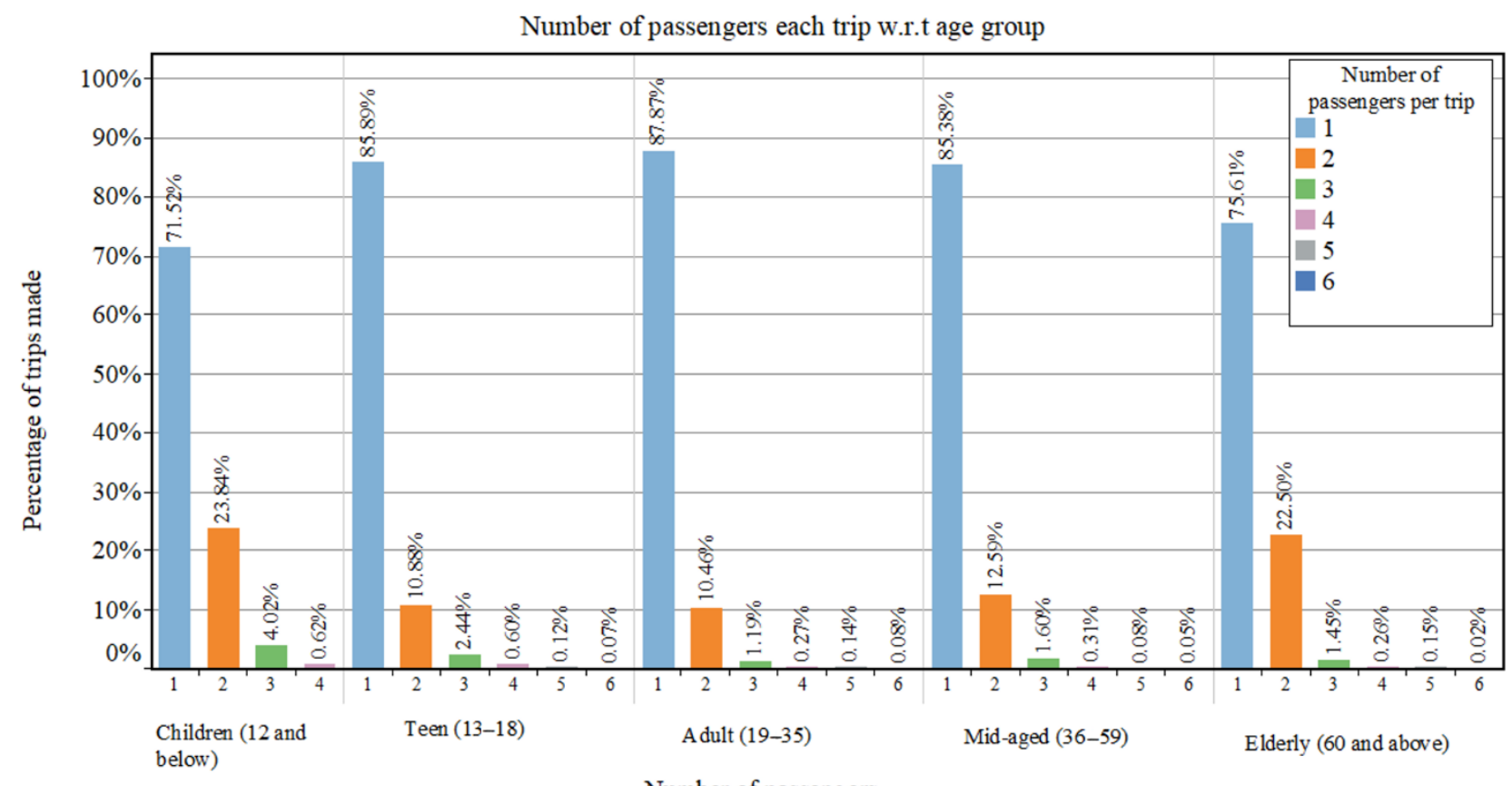

Figure 7. A plot demonstrating the percentage of trips that occur with different numbers of passengers in the same trip for different age groups. Elderly individuals and children have a higher tendency to travel with others.

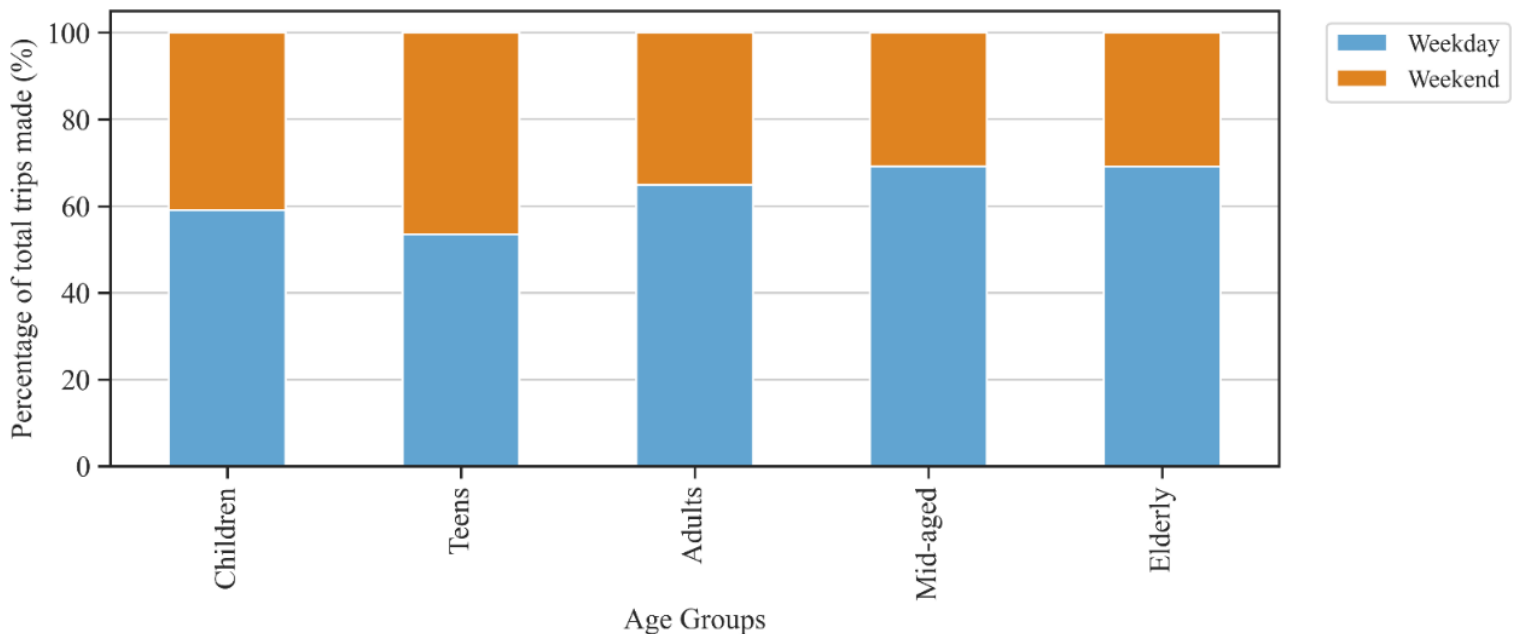

Figure 8. A plot demonstrating the percentage of trips made by different age groups during weekends and weekdays. Children and youths make trips more often on weekends.

\subsection{Environmental Factors}

Environmental factors, which refers to weather conditions, have a strong impact on the mobility of residents. This phenomenon is demonstrated in Figure 10, where bad weather conditions, such as rainy days, stormy days, and snowy days, limit residents' mobility and willingness to travel. 

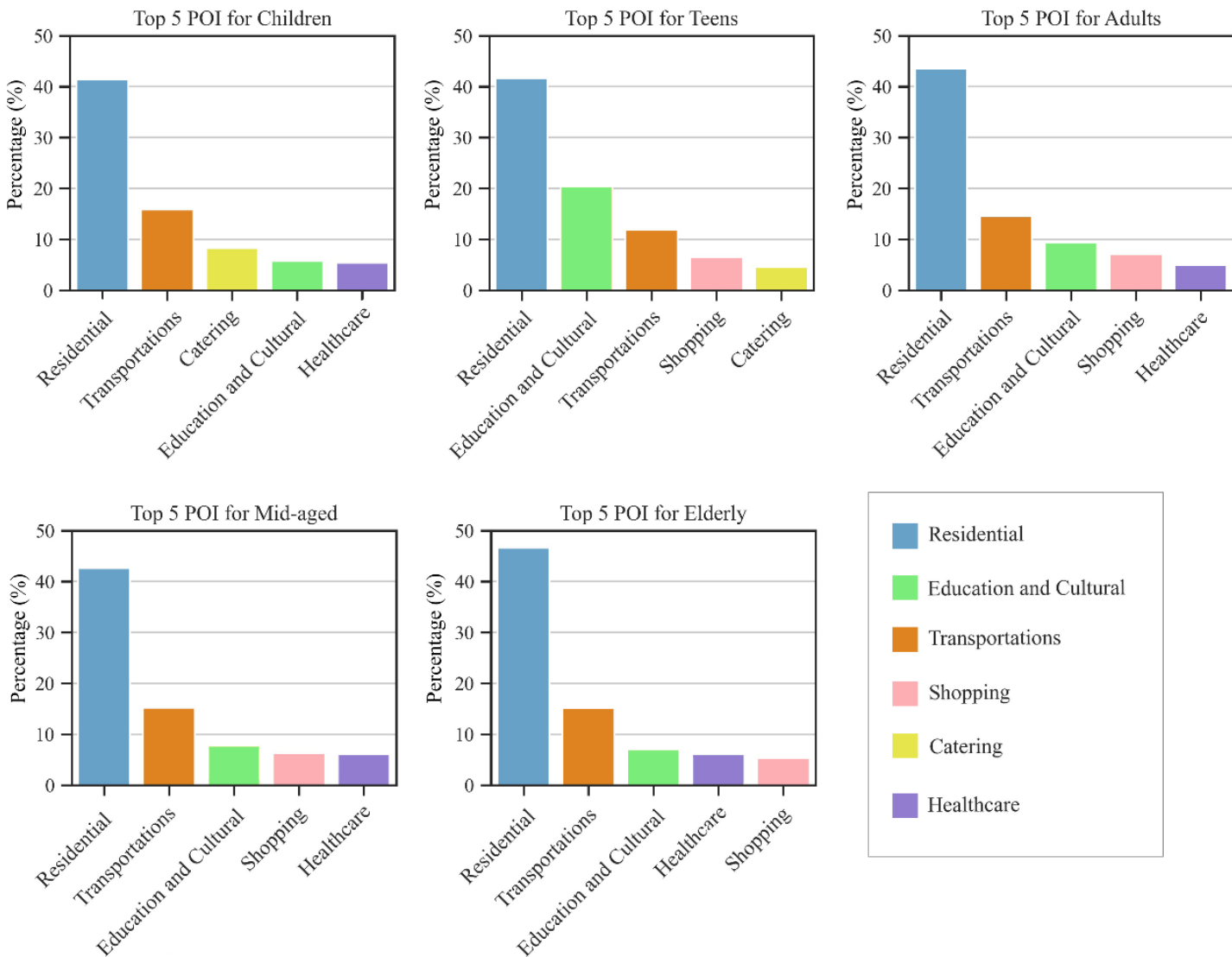

Figure 9. A plot demonstrating the top 5 POIs for different age groups based on the percentage of total trips made by the respective age groups. Youths tend to travel more to catering and transportation facilities.

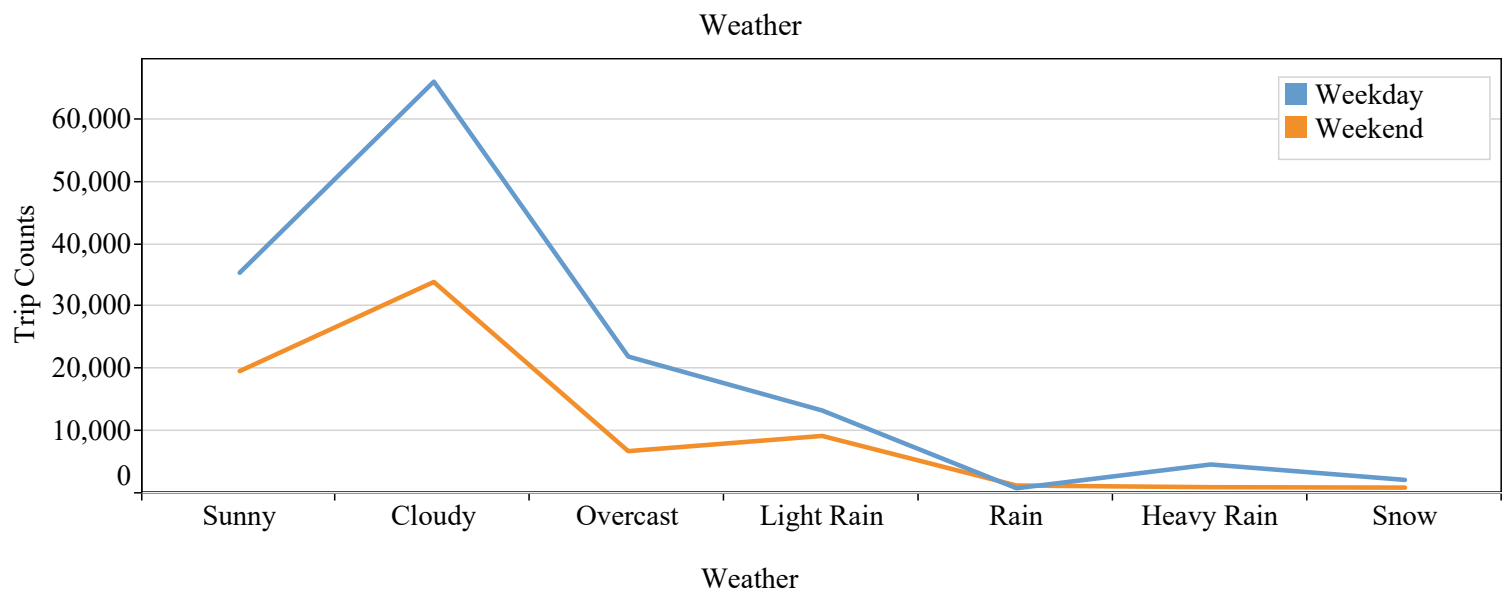

Figure 10. A plot illustrating the statistics of trips made under different weather conditions, revealing a strong impact of weather on passenger mobility.

\section{Demand Forecasting of Intercity Car-Hailing Travel}

\subsection{Methodology}

Geographical data are widely utilized in geography, economics, environmental science, and many other fields. The first law of geography emphasizes that spatial correlations appear greater between closer objects. Initially, the OLS method was used to deal with problems of multivariate linear regression. GWR was then designed by Brunsdon in 
1996 [26] to explore the spatial stationarity of spatial data, serving as a remarkable solution to spatial correlation. The fundamental formula is as follows [27]:

$$
Y_{i}=\beta_{0}\left(u_{i}, v_{i}\right)+\sum_{k} \beta_{k}\left(u_{i}, v_{i}\right) X_{i k}+\varepsilon_{i}
$$

Each $i(i=1,2, \ldots, n)$ represents a spatial grid; $X_{i k}$ represents the value of $k$ th $(k=$ $1,2, \ldots, m)$ variable of grid $i ; \varepsilon_{i}$ is the residual of the actual value and fitting value; $\left(u_{i}, v_{i}\right)$ represents the coordinates of the center point of the grid; $\beta_{0}\left(u_{i}, v_{i}\right)$ is the intercept; and $\beta_{k}(u, v)$ is the spatial geographic location function.

In this paper, 13 features are selected as the independent variables: catering POIs, healthcare POIs, recreational and entertainment POIs, tourist destination POIs, residential POIs, accommodation POIs, finance and insurance POIs, cooperative and business POIs, government POIs, educational and cultural POIs, transportation POIs, GDP, and population density, where $m$ equals 13 . Moreover, $n$ equals 978 , referring to the 978 grid units contained in the study area.

After 978 repetitions, the formula can be written in matrix form:

$$
Y=\beta X+\varepsilon
$$

where $Y$ equals $\left(Y_{1}, Y_{2}, \ldots, Y_{n}\right)^{T}$, meaning the number of passengers in the 978 grids; $\beta$ is a matrix with a size of $n \times(m+1)$, representing the coefficient for the 13 dependent variables in the 978 grids and the intercept. $\boldsymbol{X}$ is the feature matrix with $(m+1)$ rows and $n$ columns, consisting of $X_{i k}$ mentioned above and an extra intercept.

Given coordinates $\left(u_{p}, v_{p}\right)$, the regression coefficient is estimated by the locally weighted least square method:

$$
\min \sum_{i=1}^{n}\left[y_{i}-\sum_{k=1}^{m} \beta_{k}\left(u_{p}, v_{p}\right) X_{i k}\right]^{2} \times w_{i}\left(u_{p}, v_{p}\right)
$$

The formula can be estimated by the following matrix operation:

$$
\hat{\boldsymbol{\beta}}\left(u_{p}, v_{p}\right)=\left(X^{T} \boldsymbol{W}\left(u_{p}, v_{p}\right) \boldsymbol{X}\right)^{-1} \boldsymbol{X}^{T} \boldsymbol{W}\left(u_{p}, v_{p}\right) \boldsymbol{Y}
$$

where $\boldsymbol{W}\left(u_{p}, v_{p}\right)$ is a diagonal matrix with diagonal elements $w_{i}\left(u_{p}, v_{p}\right)$, usually calculated by a Gaussian function:

$$
\begin{gathered}
W\left(u_{p}, v_{p}\right)=\operatorname{diag}\left[w_{1}\left(u_{p}, v_{p}\right), w_{2}\left(u_{p}, v_{p}\right), \ldots, w_{n}\left(u_{p}, v_{p}\right)\right] \\
w_{i}\left(u_{p}, v_{p}\right)=\exp \left(-\left(\frac{d_{i p}}{b}\right)^{2}\right)
\end{gathered}
$$

In the formula above, $d_{i j}$ represents the Euclidean or Manhattan distance between $\left(u_{i}, v_{i}\right)$ and $\left(u_{j}, v_{j}\right) ; b$ is the bandwidth, the most important coefficient for GWR, representing the attenuation parameter of $W_{i j}$.

In this paper, bandwidth is chosen based on the Akaike information criterion (AICc) [28] to measure the model performances between OLS and GWR. Note the following:

$$
\begin{gathered}
\hat{Y}(b)=L(h) Y \\
\hat{\varepsilon}=Y^{T}\left(I_{n}-L(b)\right)^{T}\left(I_{n}-L(b)\right) Y \\
A I C c(b)=\log \left(\frac{1}{n} \hat{\varepsilon}^{T} \hat{\varepsilon}\right)+\frac{n+\operatorname{tr}(L(h))}{n-2-\operatorname{tr}(L(h))}
\end{gathered}
$$


The best bandwidth is chosen based on the following:

$$
b_{0}=\underset{b>0}{\operatorname{argmin}} A I C c(b)
$$

\subsection{Model Results and Discussion}

A total of 224,822 orders were divided into 978 grid units with a size of $500 \mathrm{~m} \times 660 \mathrm{~m}$. The number of buildings at each POI in each grid was obtained from the Amap developer application programming interface (API). The GDP and population density [29] of each county were retrieved from the Ning Xia Statistical Yearbook 2020 and then assigned to each grid. Thirteen independent POI variables were selected: catering POIs, healthcare POIs, recreational and entertainment POIs, tourist destination POIs, residential POIs, accommodation POIs, finance and insurance POIs, cooperative and business POIs, government POIs, educational and cultural POIs, transportation POIs, GDP, and population density. Shopping POIs and domestic POIs were excluded on statistical grounds. Passenger flows served as the dependent variable.

Considering that intercity travel has more specific routes than pure car-hailing travel, which implies great aggregation in certain addresses, our data contain order records from two fleets and three routes. The Dawukou Fleet contains two routes, with one route from the Dawukou district to Yinchuan Hedong Airport and the other route from the Dawukou district to Yinchuan. The Huinong Fleet contains only one route from the Huinong district to Yinchuan Hedong Airport. Aggregation is remarkably shown in a single route to the airport, as only 181 grids are occupied by the Huinong Fleet, while the destinations of the route to the urban district are distributed in more grids (978). In our study, all routes were included as real travel scenarios.

\subsubsection{Model Results}

Table 2 shows the results of the OLS model first used to identify the general influence of each independent variable on ridership. The adjusted $R^{2}$ is only 0.61546 , indicating that the OLS model has a terrible fit to the data. The AICc of the OLS model is 152.651687, which explains the poor performance of the OLS model. The variance inflation factor (VIF) of each variable varies below 7.5 , indicating that there is no multicollinearity. Significant results are observed for five variables: residential POIs, finance and insurance POIs, government POIs, transportation POIs, and GDP. GDP and population density cannot be directly compared with POIs given the differences in their units. Attention should be paid to the relative size of the GDP coefficient. Given the characteristics discussed above, the coefficients suggest that areas with a larger number of people receive more orders and that most orders come from travelers traveling from economically undeveloped areas to developed areas, which explains the negative coefficient of GDP. Different from previous studies $[8,9,30]$, the variables were analyzed from a global perspective, and it was impossible to explore how the built environment influences intercity ridership in the specific grid drawn. Therefore, a GWR model was applied for further analysis.

The GWR result is a coefficient matrix with a 978-grid sample and 13 independent variables. Table 3 presents the minimum, maximum, standard deviation, and average values for every independent variable. The standard deviation of every variable except healthcare POIs remains at a high level, emphasizing strong regional differences. Tourist destination POIs, residential POIs, finance and insurance POIs, transportation POIs, and GDP show larger geographical relevance. Every variable has a corresponding grid where it makes the greatest contribution to the estimated value. Among the variables, residential POIs have the highest deviation, varying from -19.3051 to 39.1386 , which indicates large regional relevance and requires further analysis. Recreational and entertainment POIs are also excavated by the GWR model as a supplement to the OLS results. Healthcare POIs show higher spatial stability than other variables. 
Table 2. Results of the OLS model.

\begin{tabular}{cccc}
\hline Variables & Coefficient & Probability & VIF \\
\hline Catering & 1.2171 & 0.2286 & 3.0911 \\
Healthcare & 0.489 & 0.876 & 2.3846 \\
Recreational and Entertainment & 4.4142 & 0.5062 & 2.3211 \\
Tourist Destinations & 1.0796 & 0.876 & 1.1567 \\
Residential & 26.5973 & $0.0467 *$ & 1.607 \\
Accommodation & 0.8939 & 0.6437 & 1.1045 \\
Finance and Insurance & 22.4362 & $0.0054^{*}$ & 2.5111 \\
Cooperative and Business & 2.689 & 0.0702 & 1.2942 \\
Government & 10.1049 & $0.0127^{*}$ & 1.651 \\
Educational and Cultural & 3.6359 & 0.326 & 2.3579 \\
Transportation & 27.6199 & $0.0211^{*}$ & 3.0639 \\
GDP & 3.8913 & $0.0204 *$ & 1.6436 \\
Population Density & 1.9701 & 0.9975 & 1.696 \\
AICc & & 152.651687 & \\
Adjusted R & & 0.61546 & \\
\hline
\end{tabular}

*indicates Probability $<0.05$.

Table 3. Results of the GWR model.

\begin{tabular}{ccccc}
\hline Variables & Average & SD & Min & Max \\
\hline Catering & 3.0426 & 3.2135 & 0.6530 & 11.5928 \\
Healthcare & 4.4072 & 0.8259 & 0.5810 & 4.7861 \\
Recreational and Entertainment & 10.0518 & 5.2089 & -0.8773 & 22.5639 \\
Tourist Destinations & 1.1096 & 15.8400 & 0.6185 & 20.5600 \\
Residential & 18.8848 & 25.0930 & -19.3051 & 39.1386 \\
Accommodation & 0.7994 & 1.7697 & 0.2123 & 7.5606 \\
Finance and Insurance & 25.4217 & 18.3834 & 10.8723 & 50.0845 \\
Cooperative and Business & 4.4969 & 1.2047 & -0.6429 & 5.2938 \\
Government & 13.4409 & 5.1722 & 3.7045 & 28.6004 \\
Educational and Cultural & 1.0443 & 6.8509 & -1.9219 & 8.8327 \\
Transportation & 11.2804 & 10.6071 & 3.6751 & 49.5164 \\
GDP & 4.2018 & 15.1682 & -4.7371 & 19.1202 \\
Population Density & 0.8341 & 2.7188 & 0.5663 & 13.4754 \\
AICc & \multicolumn{3}{c}{0.812 .85317} \\
Adjusted R
\end{tabular}

As summarized in Table 4 , the adjusted $\mathrm{R}^{2}$ in the GWR model is 0.2 higher than that in the OLS model, reaching 0.81324 and indicating that nearly $80 \%$ of the results are explainable. These comparisons make it clear that the GWR model is more suitable for analyzing geographical data. The AICc value decreases from 152.651687 to 112.895317 , showing that the GWR model is a better fit. However, the AICc value of 112 is still higher than the general car-hailing data [14], demonstrating that there are obvious spatial aggregation characteristics in intercity travel.

Table 4. Diagnostics of the OLS and GWR models.

\begin{tabular}{ccc}
\hline Diagnostics & OLS & GWR \\
\hline $\mathrm{R}^{2}$ & 0.74033 & 0.85279 \\
Adjusted R & 0.61546 & 0.81324 \\
AICc & 152.651687 & 112.895317 \\
Bandwidth & & 0.437914 \\
MSE & 89.236536 & 55.863785 \\
\hline
\end{tabular}

\subsubsection{Intercity Car-Hailing Travel Demand Forecasting Results}

The ridership for each grid is described in this section. Different colors are painted according to the size of values, which allows a clear overview of the spatial distribution of 
ridership and other variables. As many relevant studies did, we fold prediction maps of different models, and consequently, the effect of residential POI, as well as transportation POI, is analyzed from a temporal and spatial view. For prediction, the MSE of GWR is 55.863785 , which is 33.372751 lower than that of OLS.

In Figure 11, grids are painted with distinct colors, from blue to red, based on the ridership count. The ridership counts are then compared with the estimated OLS and GWR values for the Yinchuan district simply and intuitively. Better performance is observed with the GWR model than with the OLS model. Figure 11a shows that orders are mostly concentrated in the blue regions of Yinchuan, whose orders are far higher than those of the surrounding areas. The OLS and GWR estimations retain this trend but behave conservatively in the prediction of the surrounding flow. Figure 11c appears closer to Figure 11a than to Figure 11b.

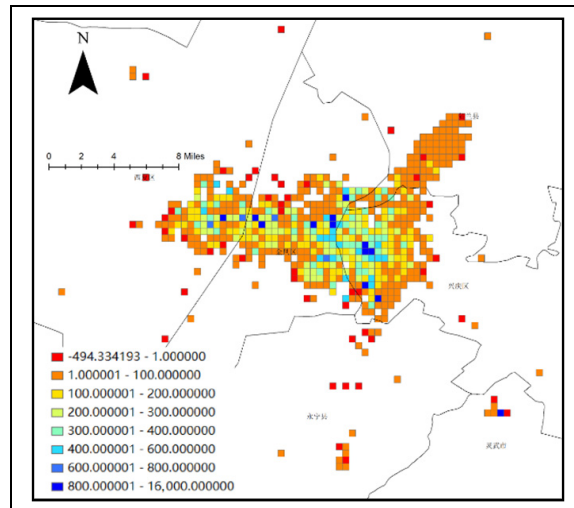

(a)

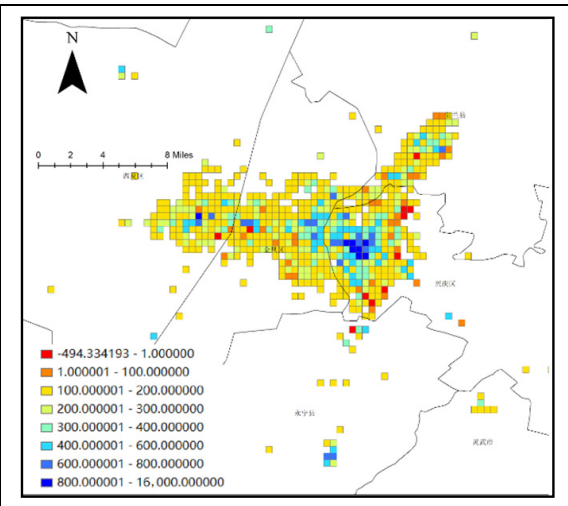

(b)

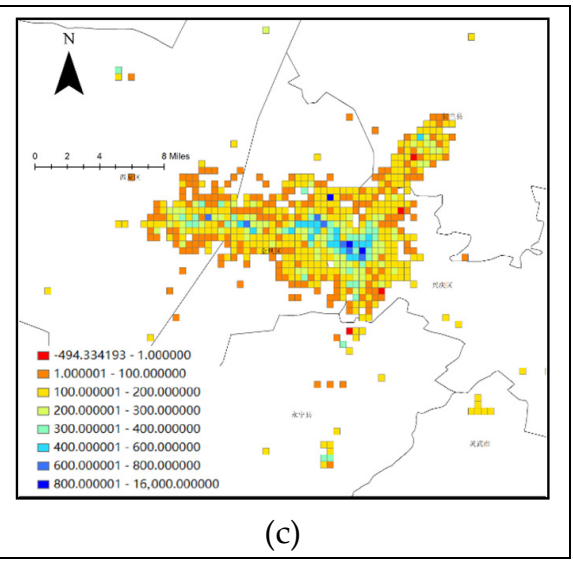

(c)

Figure 11. Comparison chart of the actual ridership and the forecast ridership: (a) order distribution, (b) OLS estimation, and (c) GWR estimation.

The results for Yinchuan are then isolated for a more in-depth analysis. From the above discussion, tourist destination, residential, finance and insurance, government, and transportation POIs are highlighted as having strong spatial heterogeneity. The statistical analysis in Section 3 finds that residential and transportation POIs appear to be the main source of passengers, and they are also found to have large spatial heterogeneity with a high standard deviation. Consequently, the distributions of POIs and the coefficients for residential areas and transportation are further analyzed. Figure 12 compares the results and GWR coefficients of residential POIs. It more clearly appears that residential orders mainly come from people in the Dawukou district of Shizuishan. As the capital of Ningxia Province, Yinchuan is the most developed city in this region, and citizens tend to undertake intercity travel to Yinchuan for different reasons and then return to the Dawukou and Huinong districts where they reside. Based on this interpretation, despite the larger population in Yinchuan, the main passengers taking buses from Yinchuan are not Yinchuan locals. Therefore, places with a higher concentration of residences do not appear to be the center of orders and the coefficient, as shown in Figure 12c,e.

Figure 13 compares the numbers and GWR coefficients of transportation POIs. Yang et al. [8] emphasized that car-hailing does not supplement public transport modes such as public buses; rather, it is a competitor. People tend to spend less on car-hailing services if public transport is more available. In Figure $13 \mathrm{a}, \mathrm{b}$, stations and road intersections are highlighted, but the demand coefficient is far larger in Shizuishan than in Yinchuan. We conclude that intercity car-hailing travel is mainly used to meet the needs of Shizuishan locals [31]. Passengers tend to undertake intercity travel from their homes to a transportation hub and back home from Yinchuan, which is in line with the observations made in Section 3. The purpose of intercity travel is very clear. 


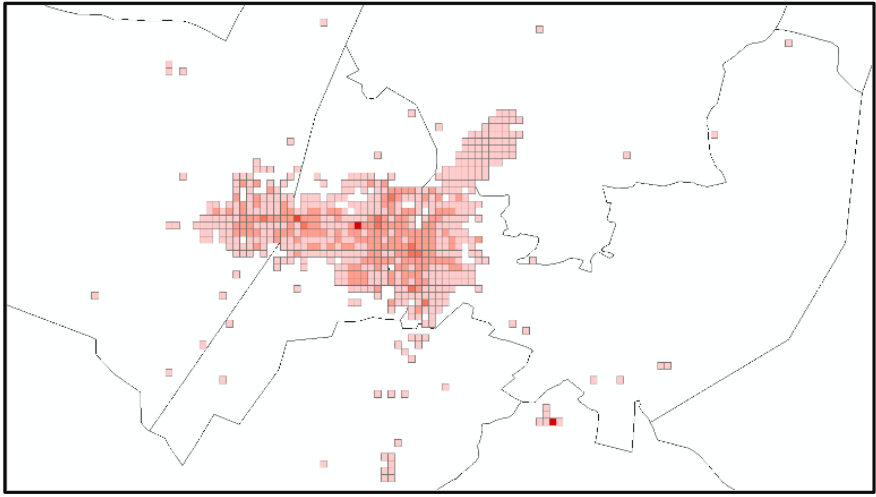

(a)

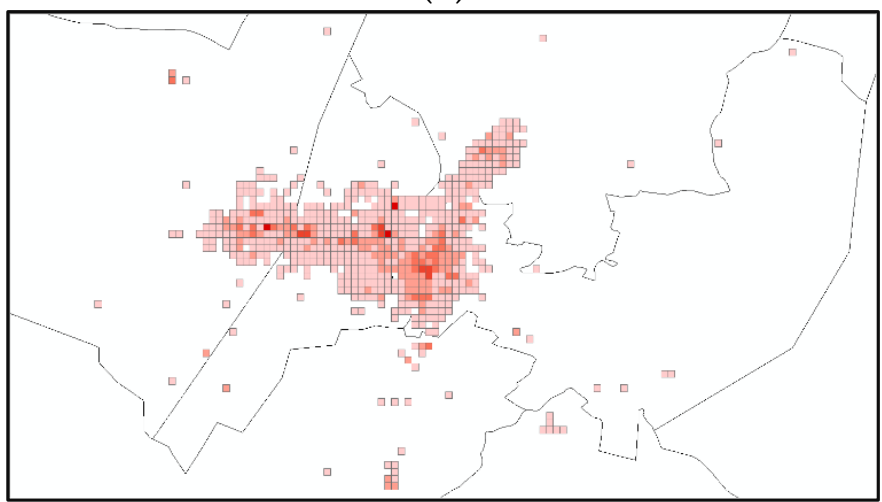

(c)

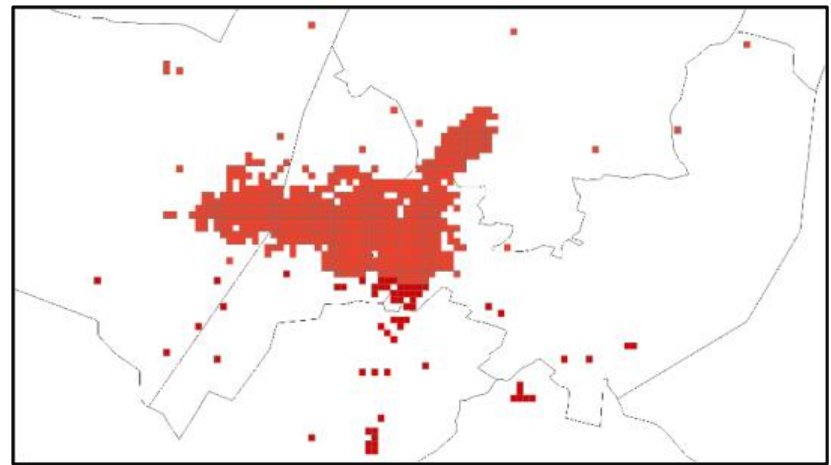

(e)

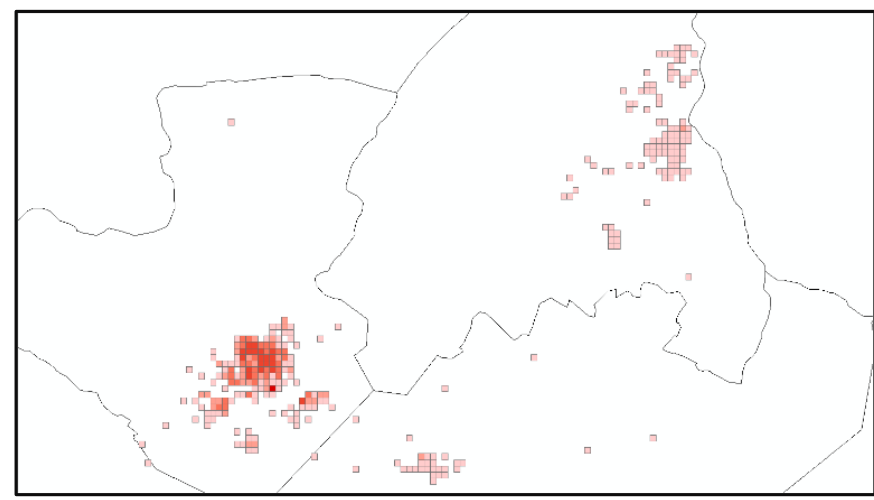

(b)

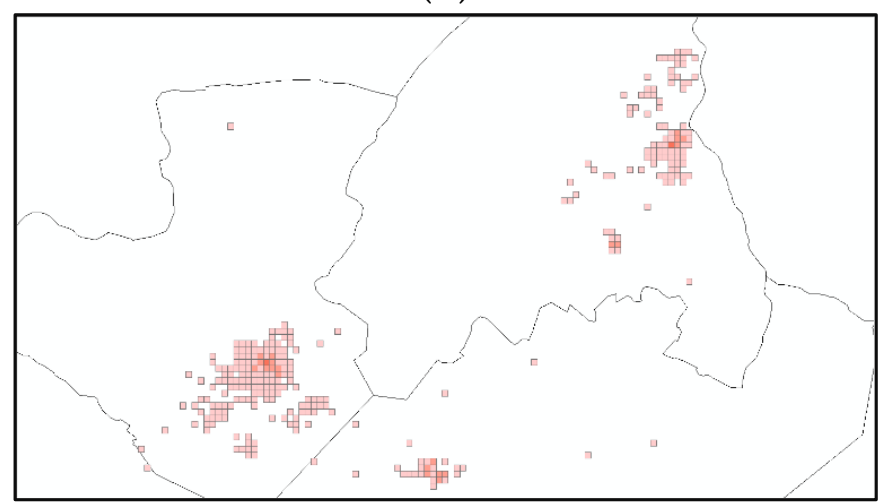

(d)

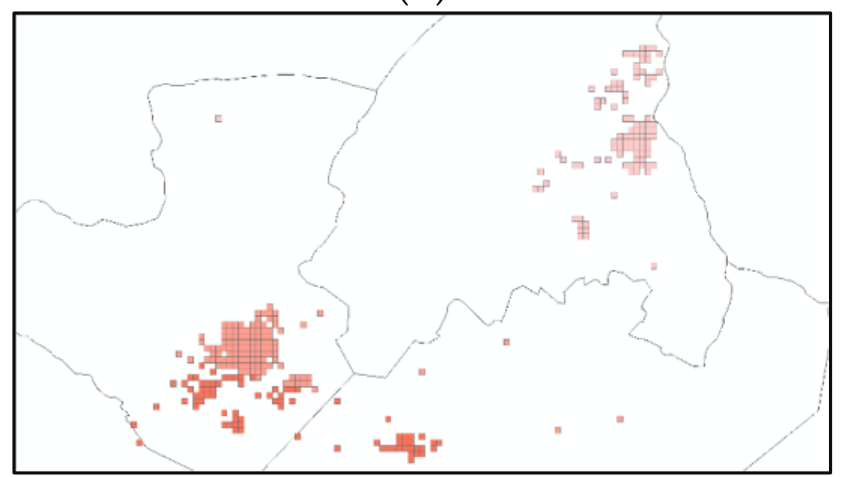

(f)

Figure 12. Comparison chart of POI numbers and coefficients (residence). (a) Order distribution in Yinchuan. (b) Order distribution in Shizuishan. (c) Number of residential POIs in Yinchuan. (d) Numbers of tourist destination POIs in Shizuishan. (e) Coefficient of residential POIs in Yinchuan. (f) Coefficient of tourist destination POIs in Shizuishan. 


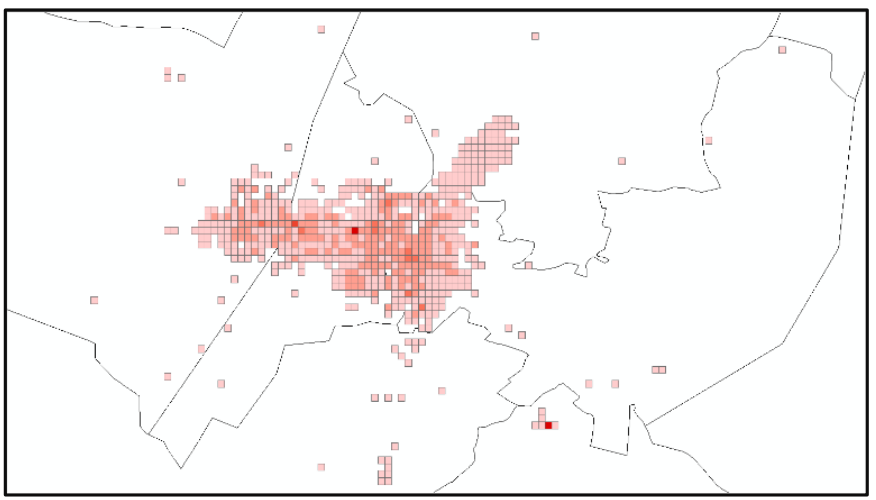

(a)

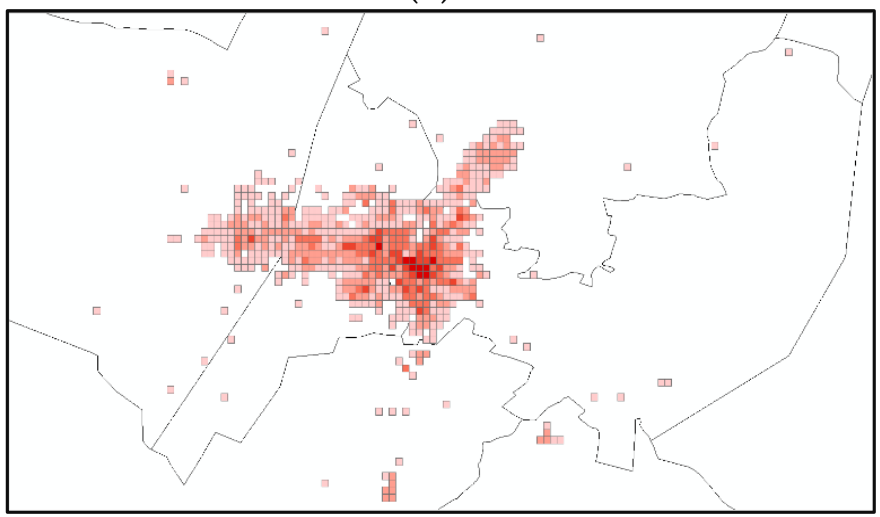

(c)

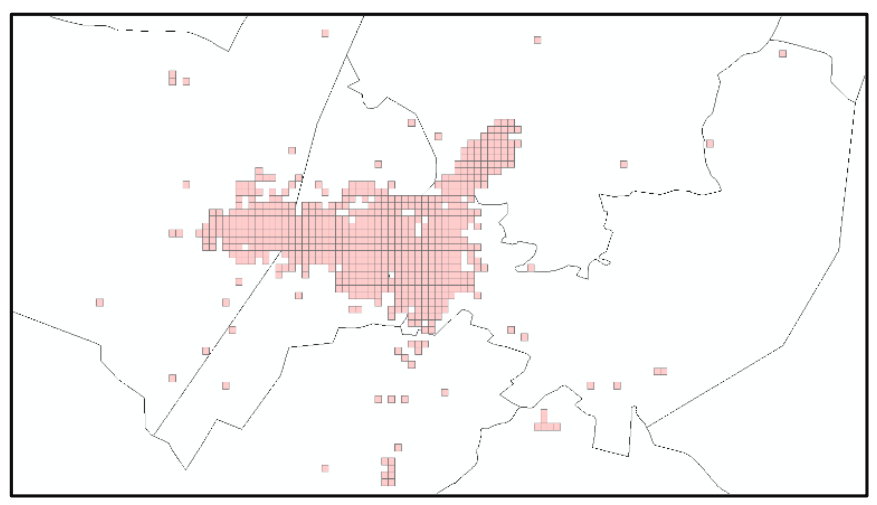

(e)

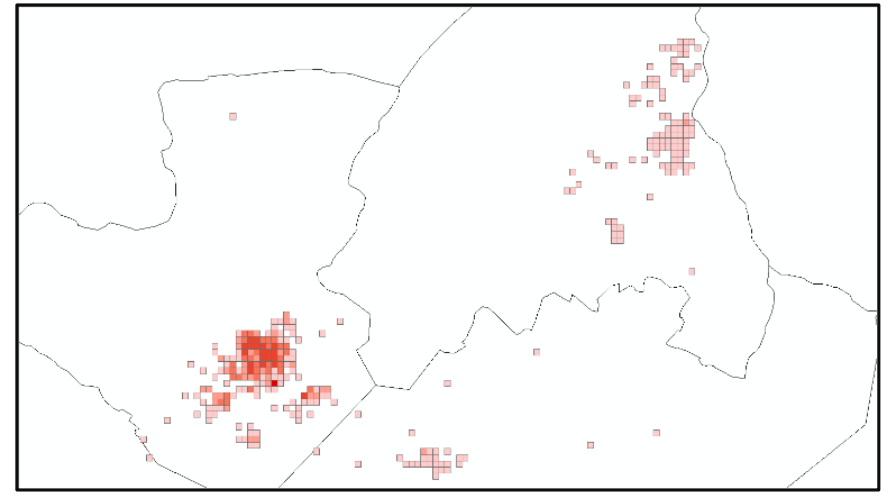

(b)

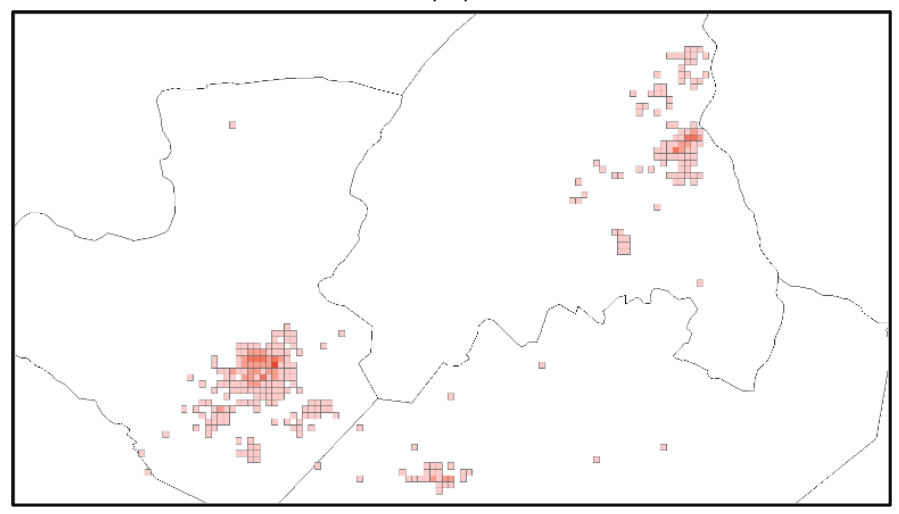

(d)

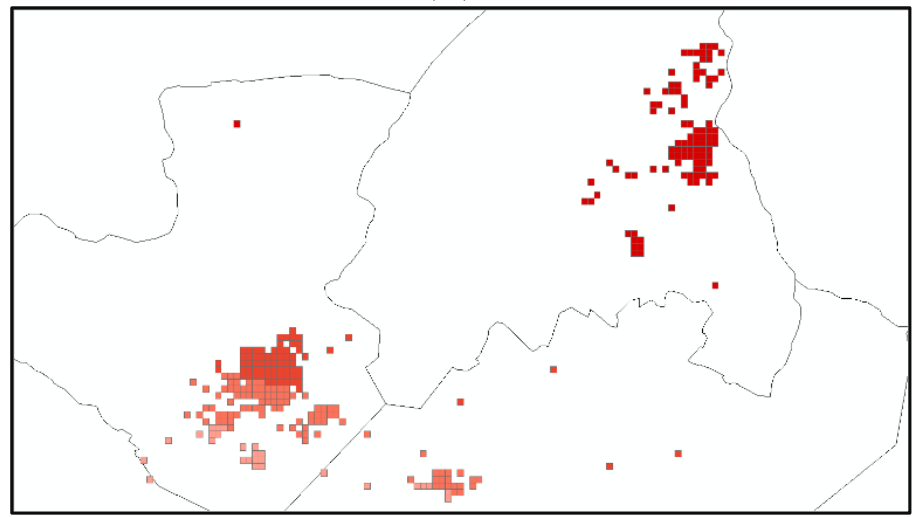

(f)

Figure 13. Comparison chart of POI numbers and coefficients (transportation). (a) Order distribution in Yinchuan. (b) Order distribution in Shizuishan. (c) Number of transportation POIs in Yinchuan. (d) Number of transportation POIs in Shizuishan. (e) Coefficient of transportation POIs in Yinchuan. (f) Coefficient of transportation POIs in Shizuishan.

\section{Conclusions}

The development of urban agglomerations has led to the gradual increase in demand for intercity travel, making intercity car-hailing travel an important part of urban mobility. However, few studies have explored the influencing factors of intercity travel or forecasted intercity car-hailing travel demand. This paper used data-mining methods to explore the influence of temporal, spatial, passenger-related, and environmental factors on intercity car-hailing travel. Regarding the temporal factors, we find that highest peak hours for intercity car-hailing trips are between 16:00 and 18:00, which are significantly different from the peak hours for intracity trips. In terms of the spatial factors, residential districts and transportation facilities are the most influential factors for intercity online car-hailing travel. There exists an interesting phenomenon whereby departures from and drop-offs 
at residential districts increase as the weekend approaches and drop after Mondays. Concerning the passenger-related factors, we found that elderly individuals and children are more likely to be accompanied by other people when traveling between cities, and youths and children travel more often on weekends. With respect to the environmental factors, we found that intercity travel is largely affected by weather. Bad weather conditions, such as rainy days, stormy days, and snowy days, limit residents' mobility and willingness to travel. Based on the conclusions of the influencing factor analysis, the characteristics of intercity and intracity car-hailing travel are very different. Thus, analyzing the influencing factors of intercity car-hailing travel holds great significance.

To further study the impact of the urban-built environment on intercity car-hailing travel, this paper uses a GWR model to predict the demand for car-hailing travel in each grid. The advantage of the GWR model is that it takes into account spatial heterogeneity, and the experimental results show that the GWR model achieves better prediction accuracy than the OLS model. Additionally, the analysis results of the GWR model reflect that residential facilities and transportation facilities are important influencing factors for intercity car-hailing travel, which is consistent with the conclusions drawn from our influencing factor analysis.

Our research could help city managers better plan for intercity transportation facilities and improve travel policies, and it can also help online car-hailing companies more accurately deploy vehicles for intercity travel. However, there is still room for improvement. In future research, we will consider more intercity factors, such as city distance, to better study the influencing factors of intercity car-hailing travel. In addition, more complex models, such as geographically weighted temporal regression (GWTR) models, can be introduced to consider both the temporal and spatial heterogeneity in the demand for intercity online car-hailing travel. Furthermore, we will verify whether our findings are still valid in other urban agglomerations.

Author Contributions: Conceptualization, J.W.; methodology, Q.W.; software, F.M. and J.W.; validation, Y.R.; formal analysis, Z.C. and Q.W.; writing-original draft preparation, Y.R. and F.M.; writing - review and editing, Y.R.; visualization, Z.C. and Y.G.; supervision, J.W. and F.M.; project administration, Q.W. and Y.G.; funding acquisition, J.W. and Y.R. All authors have read and agreed to the published version of the manuscript.

Funding: This research was funded by National Natural Science Foundation of China (Grant No. 51908018) and National Natural Science Foundation of China (Grant No. U1964206).

Institutional Review Board Statement: Not applicable.

Informed Consent Statement: Not applicable.

Data Availability Statement: The datasets generated and analysed during the current study are available from the corresponding author on reasonable request.

Conflicts of Interest: The authors declare no conflict of interest.

\author{
Abbreviations \\ AIC Akaike information criterion \\ API application programming interface \\ GDP gross domestic product \\ GPS global positioning system \\ GTWR geographically weighted temporal regression \\ GWR geographically weighted regression \\ OLS ordinary least square \\ POI points of interest \\ VIF variance inflation factor \\ VMT vehicle miles traveled \\ 2SLS two-stage least squares
}




\section{References}

1. Cervero, R.; Kockelman, K. Travel demand and the 3Ds: Density, diversity, and design. Transp. Res. Part D Transp. Environ. 1997, 2, 199-219. [CrossRef]

2. Ewing, R.; Cervero, R. Travel and the Built Environment: A Synthesis. Transp. Res. Rec. J. Transp. Res. Board 2001, 1780, 87-114. [CrossRef]

3. Schaller, B. A regression model of the number of taxicabs in US cities. J. Public Transp. 2005, 8, 63-78. [CrossRef]

4. Pan, G.; Qi, G.; Wu, Z.; Zhang, D.; Li, S. Land-Use Classification Using Taxi GPS Traces. IEEE Trans. Intell. Transp. Syst. 2012, 14, 113-123. [CrossRef]

5. Tang, J.; Liu, F.; Wang, Y.; Wang, H. Uncovering urban human mobility from large scale taxi GPS data. Phys. A Stat. Mech. Its Appl. 2015, 438, 140-153. [CrossRef]

6. Fotheringham, A.S.; Crespo, R.; Yao, J. Geographical and Temporal Weighted Regression (GTWR). Geogr. Anal. 2015, 47, 431-452. [CrossRef]

7. Liu, B.; Xiong, H.; Papadimitriou, S.; Fu, Y.; Yao, Z. A General Geographical Probabilistic Factor Model for Point of Interest Recommendation. IEEE Trans. Knowl. Data Eng. 2015, 27, 1167-1179. [CrossRef]

8. Yang, Z.; Franz, M.L.; Zhu, S.; Mahmoudi, J.; Nasri, A.; Zhang, L. Analysis of Washington, DC taxi demand using GPS and land-use data. J. Transp. Geogr. 2018, 66, 35-44. [CrossRef]

9. Sun, D.; Ding, X. Spatiotemporal evolution of ridesourcing markets under the new restriction policy: A case study in Shanghai. Transp. Res. Part A Policy Pract. 2019, 130, 227-239. [CrossRef]

10. Zhang, B.; Chen, S.; Ma, Y.; Li, T.; Tang, K. Analysis on spatiotemporal urban mobility based on online car-hailing data. J. Transp. Geogr. 2020, 82, 102568. [CrossRef]

11. Bi, H.; Ye, Z.; Wang, C.; Chen, E.; Li, Y.; Shao, X. How Built Environment Impacts Online Car-Hailing Ridership. Transp. Res. Rec. J. Transp. Res. Board 2020, 2674, 745-760. [CrossRef]

12. Ding, C.; Wang, D.; Liu, C.; Zhang, Y.; Yang, J. Exploring the influence of built environment on travel mode choice considering the mediating effects of car ownership and travel distance. Transp. Res. Part A Policy Pract. 2017, 100, 65-80. [CrossRef]

13. Ewing, R.; Cervero, R. Travel and the built environment: A meta-analysis. J. Am. Plan. Assoc. 2010, 76, 265-294. [CrossRef]

14. Li, T.; Jing, P.; Li, L.; Sun, D.; Yan, W. Revealing the Varying Impact of Urban Built Environment on Online Car-Hailing Travel in Spatio-Temporal Dimension: An Exploratory Analysis in Chengdu, China. Sustainability 2019, 11, 1336. [CrossRef]

15. Liu, Y.; Wang, F.; Xiao, Y.; Gao, S. Urban land uses and traffic 'source-sink areas': Evidence from GPS-enabled taxi data in Shanghai. Landsc. Urban. Plan. 2012, 106, 73-87. [CrossRef]

16. Sohn, K.; Shim, H. Factors generating boardings at Metro stations in the Seoul metropolitan area. Cities 2010, 27, 358-368. [CrossRef]

17. Sung, H.; Oh, J.-T. Transit-oriented development in a high-density city: Identifying its association with transit ridership in Seoul, Korea. Cities 2011, 28, 70-82. [CrossRef]

18. Zhou, T.; Shi, W.; Liu, X.; Tao, F.; Qian, Z.; Zhang, R. A Novel Approach for Online Car-Hailing Monitoring Using Spatiotemporal Big Data. IEEE Access 2019, 7, 128936-128947. [CrossRef]

19. Jiang, S.; Guan, W.; He, Z.; Yang, L. Measuring Taxi Accessibility Using Grid-Based Method with Trajectory Data. Sustainability 2018, 10, 3187. [CrossRef]

20. Wang, Z.; He, S.Y.; Leung, Y. Applying mobile phone data to travel behaviour research: A literature review. Travel Behav. Soc. 2018, 11, 141-155. [CrossRef]

21. Chen, E.; Ye, Z.; Wang, C.; Xu, M. Subway Passenger Flow Prediction for Special Events Using Smart Card Data. IEEE Trans. Intell. Transp. Syst. 2019, 21, 1109-1120. [CrossRef]

22. Hahn, J.-S.; Kim, H.-C.; Kim, J.-K.; Ulfarsson, G.F. Trip making of older adults in Seoul: Differences in effects of personal and household characteristics by age group and trip purpose. J. Transp. Geogr. 2016, 57, 55-62. [CrossRef]

23. Sarjala, S. Built environment determinants of pedestrians' and bicyclists' route choices on commute trips: Applying a new grid-based method for measuring the built environment along the route. J. Transp. Geogr. 2019, 78, 56-69. [CrossRef]

24. Zhong, H.; Li, W. Rail transit investment and property values: An old tale retold. Transp. Policy 2016, 51, 33-48. [CrossRef]

25. Ji, Y.; Ma, X.; Yang, M.; Jin, Y.; Gao, L. Exploring Spatially Varying Influences on Metro-Bikeshare Transfer: A Geographically Weighted Poisson Regression Approach. Sustainability 2018, 10, 1526. [CrossRef]

26. Brunsdon, C.; Fotheringham, A.S.; Charlton, M.E. Geographically weighted regression: A method for exploring spatial nonstationarity. Geogr. Anal. 1996, 28, 281-298. [CrossRef]

27. Fotheringham, A.S.; Charlton, M.E.; Brunsdon, C. Geographically weighted regression: A natural evolutionof the expansion method for spatial data analysis. Environ. Plan. A 1998, 30, 1905-1927. [CrossRef]

28. Akaike, H. Information Theory and an Extension of the Maximum Likelihood Principle. In Second International Symposium on Information Theory; Kotz, S., Johnson, N.L., Eds.; Academia Kiado: Budapest, Hungary, 1973; pp. 267-281.

29. Choi, K. The influence of the built environment on household vehicle travel by the urban typology in Calgary, Canada. Cities 2018, 75, 101-110. [CrossRef]

30. Munshi, T. Built environment and mode choice relationship for commute travel in the city of Rajkot, India. Transp. Res. Part D Transp. Environ. 2016, 44, 239-253. [CrossRef]

31. Qian, X.; Ukkusuri, S.V. Spatial variation of the urban taxi ridership using GPS data. Appl. Geogr. 2015, 59, 31-42. [CrossRef] 